\title{
Doctoring Up a Definition
}

Britain's notorious tabloid newspapers are allegedly written to meet the readingcomprehension level of an average eightyear-old. This publication is, of course, at the opposite end of the scale. Almost all of the readership holds or aspires to the degree of Doctor of Philosophy, so the poor author is forced to raise the standard a little. Those of you who have survived the rigors of graduate school and are not known by the academic title of "professor" are accorded the honorific "doctor." In some eyes, the title conveys a sense of expertise almost beyond comprehension: It is not by accident that the longrunning BBC Television science-fiction show was called "Doctor Who" rather than "Mister Who."

The PhD is historically the oldest degree awarded by European universities, dating back to about 1250 or so, and its name is a mere statement of fact, recognizable to any liberally educated individual of the time. "Doctor" is simply the Latin for "teacher," and "philosophy" is broadly interpreted to include all branches of knowledge.

Such clarity and unambiguity were not long-lived, however. The title quickly acquired other meanings, and one of these has overtaken the first. Introduce yourself as Dr. Smith and you are going to be asked your opinion about a rash or a persistent headache, or worse. Occasionally, you might be asked if you are a "real doctor" or "just a PhD?" Arguing that the "PhD" is indeed the real doctor and an MD is nothing more than a glorified master's degree ("Master of Doctoring") is not going to get you anywhere at that cocktail party. Let not the origins of the medical usage lead you into argu-

ments either-just take comfort in knowing that the first recorded use of the word in reference to the medical profession (in 1377, according to the Oxford English Dictionary) describes would-be healers as "Doctors of Death." The phrase makes use of an earlier meaning of the term "doctor" as one highly knowledgeable in the given subject, and refers to the general ineptitude of the Renaissance medical profession. Curious how a word can evolve a meaning almost diametrically opposite to its original intent.

\section{Occasionally, you might be asked if you are a "real doctor"} Or "just a PhD?"

The physicianly definition is only the sixth of 13 meanings given by the venerable OED. The first few definitions of "doctor" are reasonably respectable-at least if teaching is still a respected profession or learning a respected goal. Things start to go a little awry right after the medical definition (or right before it, depending on your perspective). A doctor can be a mending tool, fish of the genus Acanthurus, a particular type of artificial fly used as a lure by an angler, adulterated liquor, a ship's cook, or a loaded die used to defraud a gambler. The last of these is a little too close to the truth. How many "doctors" do you know who are as easily predictable in their answers as loaded dice?

The 13 definitions in the OED notwith- standing, "doctor," as a noun, nowadays refers mainly to a healer, or perhaps, with our ever-lowering expectations, a mechanic of the human body-or perhaps, with a stretch, a mending tool. As a verb, the word carries a distinct implication of adulteration: "He doctored those results so they would look better."

Oh, the title has its charms to the freshly minted PhD and his or her proud parents, but it is a burden too. Suppress that urge to respond when you finally hear that slightly nervous phrase, "Is there a doctor in the house?" Given the variety of secondary definitions and their negative connotations, perhaps it is a title that is best ceded to the physicians at the cocktail parties. Even they choose to give it up upon reaching the rank of "consultant" a rank of distinction in the British medical hierarchy-and revert to a mysteriously elevated "Mr." or "Ms."

In the United States, at least, those who earn a PhD degree in materials science and engineering have, at best, a $20 \%$ chance of entering the academic profession, and even less of becoming a tenured professor; so more than $80 \%$ of you doctors do not teach to earn your living, and the primary $O E D$ definition (as a teacher) does not apply.

And what of the professors out there? Surely they are those who "profess," which is a verb that has a wonderfully delicate shade of meaning all its own, implying a subtle doubt of the validity of the "professed" claim. Is there no untainted title by which we may make our way in this world? Probably not. All titles are simply a form of vanity, and all vanity invites mockery, so just call me "Alex."

ALEX KING 